\title{
Discussion and Analysis on the Function of College Students' Study Tour under the Theory of Defamiliarization
}

\author{
Hui Jin \\ Shandong Foreign Languages Vocational College \\ Rizhao, China 276826
}

\begin{abstract}
This paper discusses and analyzes the function of college students' study tour the educational function, fully elaborates the educational function, learning function and entertainment function of college students' study tour, and puts forward the countermeasures to promote the effective realization of college students' study tour function, the interaction system between study tour and humanistic tourism resources as well as the institutional guaranty to achieve the function of college students' study tour. Based on the theory of defamiliarization, this paper highlights the practical significance of off-site study tour for the realization of the function of college students' study tour and then gets conclusion.
\end{abstract}

Keywords - the theory of defamiliarization; college students' study tour; function

\section{INTRODUCTION}

For the concept of study tour, scholars put forward different points of view, and so far there is no a uniform clear statement. In this paper, author believes that the so-called study tour refers to a certain tourism behavior of "learning" and "travel" outside the permanent residence place, with tourist resources as the carrier to broaden view, increase knowledge, enrich experience, and improve the overall quality. It should be noted that the study tour must make "learning" and "travel" combined, not focusing on "learning" but ignoring "travel", or vice versa. The existing study tour is divided into three types, that is outbound study tour, inbound study tour, domestic study tour. This paper makes elaboration only on the domestic study tour.

As a special type of tourism, the unique off-site tour makes the subject of tourism in face of the things that have no attention paid to a familiar sight produce new feelings and discoveries, so as to effectively inspire their inner emotions, and further to effectively play positive energy and internalize it into their cultivation and strength, improve the feasibility of quality education. This is also the essence of application of the theory of defamiliarization in college students' study tour.

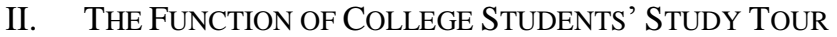

\section{A. Educational Function}

The uniqueness of the study tour is the "combination of learning and travel" and the "equal emphasis on learning and travel", emphasizing the unity of culture and economy and of tourist and educational functions. [1]

1) Iinherit and carry forward the fine traditional culture: Qufu is the origin of Chinese Confucian culture, where the China's first study tour festival- Confucius Study Tour Festival was held in 2006. On the opening ceremony of Qufu Confucius Research and Study Tourism Festival in 2006, Qufu is awarded the honorary titles of "China research and study tour destination" and "national research and study tour demonstration base". In February 2017, the General Office of the CPC Central Committee and the General Office of the State Council issued the Opinions on Implementing the Heritage and Development of Excellent Traditional Culture in China, in which it is pointed out to greatly develop cultural tourism, make full use of the advantages of historical and cultural resources, plan and design a series of special research and study tour line, and guide tourists to feel and know Chinese culture in the cultural tourism.

It is undoubted that the development of study tour with Qufu as the core destination can greatly help college students deeply understand the Family-Country thinking, ritual thinking, educational thinking and so on in the traditional culture. Through the tour of the Mansion, Temple and Cemetery of Confucius, the Confucius Six Arts City and the Mount. NiShan and other attractions, the educational functions of study tour is fully reflected in the tourist resources that are contained in the construction, painting, couplets and inscriptions on the tablet and stele, story and legend, animals and plants and others. It gives very good explanation on how to correctly understand the difference between the Chinese and Western cultures, the conflict between traditional culture and modern civilization, and how to protect the excellent traditional culture. It can inspire students to have sense of shame and make the Shame Culture carried forward and further create a kind of cultural traditions passed down by generation to generation. 
2) Inspire student's patriotism, making them love and loyal to their motherland: College students should be righteous, honest and kind. The tour of Jinggangshan and other old revolutionary areas, revolutionary base areas, celebrity temples, martyrs cemetery, the former residence of the great man and the experience of long-march road, etc., fully inspire their patriotic feelings. For example, in the Yuewangmiao temples across the country, everyone is moved by Yue Fei's righteousness and loyalty and influenced by Yue Fei's heroic style, who had repaid the country with supreme loyalty and patriotism and whose heroic spirit can whelm the heaven and earth; but everyone spits and disdains the Qin Hui couple in a kneeling statue, whose faces are blackened seriously, and even someone spit them and throw eggs at them, which is a direct expression and catharsis of people's attitude to the crafty villain. But from the viewpoint of environmental protection, such radical behavior is not advocated. From these, it can be seen that the negative characters and examples in study tour also play a educational function for college students, making them find own and other evils to get introspective, making them have sense of shame and seek for goodness, easy to distinguish the right and the wrong, and finally internalized into their moral cultivation.

3) Be devoted to the motherland's economic construction, not forget national humiliation: As time goes by, many historical trauma has gradually been diluted in the mind of young people, with the historical scar only remained in a few lines of text schoolbook, and many young students visit the Yuanmingyuan only to take a photo together with the the historical remnants, and no longer bring the historically humiliated invasion and appalling plunder to mind. The Past Not Forgotten is a Guide for the Future. Forgetting the history is the betrayal of the past. Therefore, we should make students visit the martyrs cemetery, commemorative venues and sites such as Nanjing Yuhuatai Martyr Cemetery, Nanjing Massacre Victim Compatriots Memorial Hall, Unit 731 Crime Evidence Site, and provide them with tour guide, physical display and graphic analysis etc., to represent the inhuman humiliation when the motherland was undeveloped and had no international prestige, making students fully aware of the national honor and disgrace closely related with the interest of individual, and further clear their historical mission and social responsibility. As said by $\mathrm{Xi}$ Jinping, "when the nation prospers and ethnic group unites, we will be good [2]".

It is not enough only to have sense of shame, and only when the sense of shame is transformed into concrete action, the ultimate goal of study tour will be achieved. The comparison between the undeveloped and beaten status in the past and the prosperous and strong state today, can promote young students to love the motherland as well as its beautiful mountains and rivers, and to actively participate in the economic construction of the motherland with a quick change. We can make students visit the economically developed firsttier cities such as Beijing, Shanghai and Guangdong, and the leading enterprises with international prestige such as Huawei and Haier, to fully inspire students' national pride, and be willing to contribution to the development and prosperity of the motherland.

4) Protect cultural heritage and protect ecological balance: In our country, there are some incivilization in the tourism, such as spiting and throwing garbage anywhere anytime, climbing buildings and trees, breaking flowers and grass, freely painting and cutting and taking pictures, picking up public things on the sly and breaking the physical things, which all damaged the natural cultural heritage and material and cultural heritage at different degrees, and also caused great damage of ecological environment. The study tour makes students know the information of cultural heritage through what they see and hear personally, and understand the importance of protecting cultural heritage and the need to protect the ecological balance, making the concept of sustainable development more popular; at the same time, it also promote students to standard their behaviors, not do something harmful to the development of greening, and then influence the people around, and bring the formation of a good social ethos.

\section{B. Learning Function}

1) Make up for the shortcomings of theoretical teaching: College students have strong desire for knowledge and are fully curious about the things outside of the usual environment. As the traditional classroom mostly focuses on theoretical study, and dominated by teachers, resulting in little learning effect. What's learned from books is superficial after all, and It's crucial to have it personally tested somehow; .reading ten thousand books is like traveling ten thousand miles, so it is impossible to solve the problem of unity of knowledge and practice only by single theoretical teaching. Study tour is a bridge between theory and practice, which can effectively promote the implementation of quality education. By visiting the prestigious institutions of higher learning, such as Peking University, Tsinghua University and other famous institutions of higher learning, listening to lectures by teachers and influenced by profound and progressive campus culture, appreciating teachers' and students' high-spirited and enterprising passion, students will have their herd behavior standardized further due to the positive function of group psychology and they will clear about it is impracticable to make undisciplined words and actions, to spend time in vain, and to make no attempt to make progress. Qufu's study tour is carried out earlier, and in recent years it has been gradually integrated by some practical operation ability training, for example, seeking for the origin of Confucian culture in ZhuSi College, finishing lawn, pruning tree branches; painting cultural wall for Qufu Xingtan middle school; participating in memorial ceremony for confucius[3], to combine education with entertainment and teaching with learning, to make personal experience and change driven study into active study, so that college students improve their actual operation ability and cultivate their love 
mind and team spirit, and even solve their psychological problems, reshape their healthy personality and character.

2) Reconstruct the view pattern, conducive to regional communication and exchange: In China, there are some regional differences of economic development, cultural exchanges and other aspects between the east and the west and between the north and the south, and influenced by the sight, environment and even some outdated books, college students think some things still represent the undeveloped state, and even have a certain misunderstanding of them. Especially in the ethnic minority areas, there are rich and colorful ethnic folk customs, but some areas keep their ethnic folk customs still in the original appearance while some are advancing with the times and integrate many modern elements in the development and progress of society. These very attractive ethnic customs, often been misrepresented to become fantastic and be divorced from reality, seriously incompatible with the facts. The walking marriage of Mosuo minority is just a typical example. The study tour integrates food, residence, travel, shopping and entertainment, which can make young people understand the folk customs in different regions, so as to make communication and eliminate misunderstanding, learn respect, build friendship and avoid regional discrimination[4]. At the same time, it is also conducive for college students to become the "image speaker" of the region in the future, who can provide a correct publicity with their personal experience and correctly treat the region. So it is particularly necessary to breakthrough administrative divisions, carry out regional tourism cooperation, establish resource and information sharing, mutual tourist transportation and products complementation [5]. After having an understanding, nobody will deliberately destroy it. When a thing understood really by a person, it will become part of the person to some extent [6].

3) Increase knowledge reserves: At the beginning of the study tour, we can first intentionally know our travel destination what we want to go by means of media, friends and family, network and other channels, learn well the attractions, travel transportation, hotels, climate types, diet and so on. The individual tourist should make Travel Raiders by self, which is the most direct way to obtain knowledge. The commentary of tour guide, the guide-type graphic audio and video of attraction and what we hear and see in the tour all are an effective way to supply and increase our knowledge reserve. Whether it is the cultural connotation and knowledge of natural tourism resources or that of cultural tourism resources, whether it is the tourism knowledge from books or from mouth to mouth in the tourist destination, they all have an important role for increasing the knowledge reserve.

\section{The Entertainment Function}

Just as the so-called "beauty appears from the distance", the off-site study tour can make college students more willing to get out of the classroom and close to the nature, for they have a certain spiritual appeal for participation and experience of the unfamiliar tourist destination. Especially young students have more active thinking and it is difficult for them to focus on the commentary of tour guide for a long time. Therefore, the combination of education with entertainment is particularly important that can make college students to participate in the travel experience, and the pleasure of students in spirit becomes an important factor that can not be ignored. In addition, the entertainment functions of study tour also need the timely and correction guidance of the accompanying managers, to make a combination of entertainment and fun, school work, career and so on, and further promote the sensory stimulation of entertainment into college students' inspiration for awareness of independent entrepreneurship. The Disneyland established by Mr. Disney is just a powerful example who turns the pleasure into a career.

\section{THE INTERACTIONAL MECHANISM OF STUDY TOUR AND HUMANISTIC TOURISM RESOURCES}

All the tourism resources have the qualification and potential for development of study tourism, and in order to make the functions of study tour education, learning and entertainment presented at maximum, the study tour of college students has its very strong purpose and pertinence for selection of the tourism resources and tourism destination. Only when the two make an effective combination, can the mutual win and benefit be achieved. From the actual operation of study tour, most of the domestic study tours focus on the choice of humanistic tourism resources.

From the internal interaction, the coordination, complementarity and cooperation among the various elements of study tour can make the function of study tour be realized effectively, which is conducive to the protection and utilization of all kinds of tourism resources, especially the humanistic resources, and more give full play to the function of study tour. And the improvement of cultural demand, the protection of heritage resources, the inheritance of civilization and culture, the development of scientific research on teaching, the social national consciousness, the dissimilation of heritage tourism and so on constitute the external interaction [7]. Concretely, for the purpose of diversified tourism, under the active guidance of administrative departments at all levels of tourism, people have a higher level of choice for humanistic tourism resources in the study tour, and they are no longer confined to the traditional projects in such tourism destinations as Beijing, Shaanxi and so on, but they focus on the choice of resources with a higher cultural profundity, deeper cultural accumulation and content, such as cultural heritage tourism resources.

\section{THE SYSTEM TO ENSURE THE ACHIEVEMENT OF} TOURISM FunCTION IN COLLEGE STUDENTS' STUDY TOUR

The economic development and the advocacy of quality education make more and more families increase the investment in education of college student. In the improvement of their overall quality, college students also have more prominent subjective initiative. In the society, information is rapidly developing, the concept of lifelong learning is popularly supported by people, and people's cultural demand is increasing. Study tour has become an effective way to achieve the above demands, and the state has begun to pay attention to 
this part of tourism market and make the development and utilization.

\section{A. The Security System for Development of Study Tour}

We have a later development of study tour in China, and since 1985 , the state began to carry out the study tour in the name of the government as well as the international exchange agencies and the travel agencies and other organizations of some economically developed provinces, which mainly engaged in the inboard study tour of Japan and South Korean young people. Till July 2000, the Jiangsu Provincial Department of Education and Tourism Bureau jointly issued a document to launch the "education travel" (also known as study tour) program, for which the cross-regional cross-border education travel is widely developed among the 4.5 million students in the colleges and universities of the province [8]. It is not coincidental that the program of study tour spread in Jiangsu Province, has played a great role in promoting the development of study tour of domestic college students. After a few years, the government agencies and travel agencies at all levels began to actively launch study tour in Japan, Korea and Singapore, but they did not highlight the framework themed by college students' tour. In 2009, the Guangdong Provincial Government promulgated the "Opinions on the Trial of the National Tourism and Leisure Program in Guangdong Province", which clearly put forward, "all kinds of schools at all levels can organize teachers and students to carry out study tours during the statutory holidays such as winter and summer holidays, to include the study tour in the comprehensive practice of students", and Guangdong has become the first pilot of national tourism and leisure program" around the country [9]. This relaxes the institutions in the qualifications to organize the study tour, to make colleges and universities become the organizer of the study tour, for which we can say this is a major advance in the history of study tour. In 2009, the Beijing Municipal Tourism Bureau started the "study tour" of primary schools, secondary schools and universities, and planned to contain the "study tour" into the teaching plan of primary school, secondary school and university through coordination with the relevant departments [10], which deepened the market of study tour of college students. In December 2010, the National Tourism Administration issued the "the program of 'Twelfth Fiver-year' Development Plan of China Tourism (Exposure draft)", which proposes that the implementation of study tour activities for young people is supported as an important way to broaden their view, increase their knowledge, and make them accept patriotism education, and the study tour will be developed further and it will be included in the curriculum of primary and secondary schools as soon as possible [11], unfortunately, this development program did not include the study tour of college tour into the curriculum of universities. In 2013, the General Office of the State Council issued the " Program of National Tourism and Leisure (2013-2020)", which states that "on the premise that the total amount of holiday time is guaranteed, colleges and universities can adjust the winter and summer holiday time according to the actual conditions, and the local government can explore the arrangement of spring or autumn holiday for primary and secondary schools" [12]. The implementation of this national program, really raises the development of study tour of college students to a high degree of attention.

\section{B. Suggestions on the Development of Study Tour of College Students}

In recent years, the educational systems across the country have set up travel agencies in succession to serve the education, and now there have been more than 100 agencies [13]. But these travel agencies provide services in different fields, and they can not accurately achieve the purpose of colleges and universities to carry out the study tour. Therefore, the tourism enterprises and colleges and universities all should become active organizers, not rely solely on the traditional tourism enterprises, colleges and universities should take the initiative to participate in the market of study tour, and assume the responsibility and obligations of opening up a new platform and the second classroom for theoretical education of universities.

In pricing of study tour of college students, we should be apt to the rural students from the family with lower income, so that all students have the right to get thinking baptism, widen their view and accept study and education, and for the college students from exceptional family with low economic income, we should derate their travel expenses. In the special study tour group of college students spontaneously organized by colleges and universities, we should not take the group fees as the standard to enter the group and not select only the excellent students for participation of summer camps and other learning activities, but we should encourage the students with ordinary economic conditions and ordinary comprehensive performance to participate in it, so as to enhance their self-confidence and ambition by the way of attention on both "travel" and "learning". College students have strong group psychology, and when the overall quality of individual is improved, it will have a profound circumjacent impact and social impact.

In addition, the government can make a guidance and coordination, the enterprises provide a platform and the schools make a mobilization to jointly promote the development of study tour, by which the employment market will be opened up for college students.

\section{CONCLUSION}

The function of college students' study tour is mainly embodied in educational function, learning function and entertainment function. Combined with the theory of defamiliarization, we should make the function of college students' study tour played and reflected at maximum, which has good explanation on correct understanding of the differences between Chinese and Western cultures, of the conflict between traditional culture and modern civilization and how to protect the excellent traditional culture; to make college students distinguish right from wrong, strengthen their moral cultivation; be devoted to the construction of the motherland with their practical action, and present the ultimate goal of study tour. Meanwhile, it can make up for the lack of theatrical teaching in college class, increase the knowledge reserves of college students, eliminate the differences and discrimination between regions. In addition, the study tour in 
the perspective of defamiliarization, has also a certain role of inspiration for college students' employment and entrepreneurship in the future.

At present, the domestic study tour is mainly for the choice of humanistic tourism resources, and the destination is also a few traditional cities. From the perspective of diversified development, we can expand the development of the corresponding tourism resources, to extend the tourism destination to more cities and regions.

In order to make a better development of college students 'study tour in the perspective of defamiliarization, we also need to establish and perfect the corresponding system, raise the students' study tour to a high degree of attention, so that the study tour can give full play to its role and function.

\section{REFERENCES}

[1] Wen Hong, Sun Yuqin. Thinking on the Development of Study Tour Market. [J] Journal of Huaihua University, 2005, (01)

[2] Shi Ping. Nation Good, people Good, Everyone Will Good [J] Qiushi Journal ,2013, (06).

[3] Meng Yi. The Qufu Study Tour from Attention on "Travel" to Attention on "Learning"[N], Dazhong Daily, Aug. 19, 2014.

[4] Liu Guifen. The Design of Dongguan China International Travel Service (CITS) on youth's study tour products and its research on promotion.[D]. Guangdong: CNKI, 2013: 11.

[5] Wang Chunyan. Study on Inter-Provincial Cooperation on Regional Tourism Development [J] .Journal of Jilin Teachers College of Engineering Technology, 2009, (7): 55-58.

[6] (UK) Timothy, (UK) Boyd. Heritage Tourism [M]. chiefly translated by Cheng Jinneng. Beijing: Tourism Education Press, 2007.

[7] Zhu Jian. The Evaluation on Goguryeo World Cultural Heritage Value and the Research on Utilization of Study Tour [D]. Jilin: CNKI, 2013: 37.

[8] Shao Ling. The Program of Jiangsu Province to Implement the "Study Tour" [N]. Eastday, 2001-03-24.

[9] Baidu Encyclopedia. National Leisure Program [EB / OL]. [Sept. 20, 2013] http://baike.baidu. Com / view / 2130986.htm.

[10] Zhao Zhengyuan. Whether It Is Feasible to Include the "Study Tour" into the Teaching Plan[N]. Education of China, Feb. 2009.

[11] Tourism - China Network. The Program of the "Twelfth Five-year" development plan of China Tourism [EB / OL]. (Dec. 6, 2010) [Sept.20, 2013].

[12] Liu Qingchuan. The Ministry of Education Has Listed Suzhou and Other Places as the Collective "Study Tour" Pilots [N]. Xinhua Newspaper Network, Nov.14, 2012.

[13] Feng Guanghui. Develop the Educational Tourism Market, Protect the Brand of "Educational Tourism"[N]. China Travel News, Jan.14, 2002 (2). 